\title{
Awareness of HIV/AIDS and its routes of transmission as well as access to health knowledge among rural residents in Western China: a cross-sectional study
}

Tianqi Zhang ${ }^{1}$, Yang Miao ${ }^{1}$, Lingui $\mathrm{Li}^{2}$ and Ying Bian ${ }^{1 *}$

\begin{abstract}
Background: The purpose of this study was to evaluate the coverage of HIV health education among rural residents in western China by ascertaining their awareness of HIV/AIDS and its transmission routes, and to investigate how these residents receive health information.
\end{abstract}

Methods: A survey was conducted through stratified clustered sampling at 99 county hospitals in 11 provinces in western China. Information was collected on awareness of HIV/AIDS and its transmission routes, as well as residents' access to health knowledge. Chi-square analysis was used to analyse the differences in HIV/AIDS awareness (knowing of the existence of HIV/AIDS, hereinafter referred to as "HIV awareness rate") between different subgroups categorized by demographic status, regional factors, and different methods of access to health knowledge. To further analyse the effects of access to health knowledge on HIV awareness, a logistic regression model was established. The relationship between access to health knowledge and transmission routes was also examined using chi-square analysis.

Results: The HIV awareness rate of the total 9274 participants was $80.9 \%$. There were statistically significant differences between subgroups classified by age $\left(x^{2}=482.118, p<0.001\right)$, education $\left(x^{2}=853.465, p<0.001\right)$, occupation $\left(x^{2}=340.553, p<0.001\right)$, income $\left(x^{2}=186.448, p<0.001\right)$, cumulative HIV cases according to province $\left(x^{2}=\right.$ $59.513, p<0.001)$, per capita annual net income of rural households according to province $\left(x^{2}=64.676, p<0.001\right)$, proportion of minority population according to province $\left(x^{2}=94.898, p<0.001\right)$, direct access to health knowledge (medical staff: $x^{2}=419.775, p<0.001$; mass media: $x^{2}=740.238, p<0.001$; family members: $x^{2}=12.189, p<0.001$; socializing: $X^{2}=48.780, p<0.001$; health education activities: $\left.X^{2}=154.400, p<0.001\right)$, and indirect access to health knowledge (having a non-communicable disease with medical instructions $x^{2}=78.709, p<0.001$; physical examinations: $\left.x^{2}=135.679, p<0.001\right)$. The logistic regression model showed that education and mass media had the strongest impacts on HIV awareness among all methods of access. Participants had the least awareness of HIV's mother-to-child transmission route.

Conclusion: The HIV awareness rate indicated that previous HIV health education covered $80 \%$ of the rural population in western China. Mass media should take greater responsibility in HIV health education for the general population, and special attention should be paid to the elderly, the most impoverished population, minority community as well as the mother-to-child transmission route.

Keywords: HIV/AIDS, Awareness rate, Transmission routes, Western China, Rural residents

\footnotetext{
* Correspondence: bianying@um.edu.mo

${ }^{1}$ Institute of Chinese Medical Sciences \& State Key Laboratory of Quality

Research in Chinese Medicine, University of Macau, Avenida da Universidade,

Taipa, Macau, China

Full list of author information is available at the end of the article
}

(c) The Author(s). 2019 Open Access This article is distributed under the terms of the Creative Commons Attribution 4.0 International License (http://creativecommons.org/licenses/by/4.0/), which permits unrestricted use, distribution, and reproduction in any medium, provided you give appropriate credit to the original author(s) and the source, provide a link to the Creative Commons license, and indicate if changes were made. The Creative Commons Public Domain Dedication waiver (http://creativecommons.org/publicdomain/zero/1.0/) applies to the data made available in this article, unless otherwise stated. 


\section{Background}

The prevalence of HIV is a worldwide threat to public health. Although there is no cure for HIV, health education is considered as the most effective preventive measure. Being the most populous country, China places great importance on health education regarding HIV [1], and public education is one of the foundations of the Chinese HIV prevention and control system [1,2].

Since the first case was diagnosed in Beijing in 1985, the Chinese government added requirements for health education to all national planning documents. However, it was not until the outbreak of HIV/AIDS among intravenous drug users (IDU) in Yunnan, a southwestern province, around 1990, that HIV awareness started to grow. In the mid-1990s, the HIV epidemic among commercial plasma donors in the central provinces was exposed. At around the same time, the central government published the first outline for HIV/STD health education, requiring local governments to provide HIV health education for the general population. In 1998, the government established basic principles for HIV/STD health education, and published an official handbook of basic information on HIV/AIDS [3]. In this way, China built up a clear policy framework for HIV health education.

Before 1998, HIV health education in China was mainly motivated by a political responsibility to respond to World AIDS Day $[1,4]$. There were also disagreements about how to facilitate condom use and sexual education [5]. After 1998, the transportation, education, public security, and postal service departments, the entertainment sector, and NGOs began to play active roles in this field [3]. The central government's 2004 HIV education plan recognized that rural areas still lacked HIV knowledge, and called for attention to rural areas, especially minority communities [6]. In response, a manual written in five ethnic languages was published, and clergy members started engaging in HIV health education among minority communities $[7,8]$.

In China, one outcome of the longstanding separation between urban and rural areas is the inequality of health services [9]. The rapidly developing economic process of urbanization drives thousands of villagers into the cities. Each year, a massive migrant population mobilizes in a country-city-country cycle. Part of this "floating population" engages in commercial sex, either as commercial sex workers (CSW) or paying customers [10]. Thus, they become a bridge population carrying HIV from highprevalence cities to rural areas $[10,11]$. More than half of those with newly diagnosed HIV in 2015 were from underdeveloped rural areas [12], and knowledge of HIV was lower in these areas $[11,13]$. For these people, poor knowledge is a key factor in exposure to HIV infection and transmission [11, 14]. According to knowledgeattitude-practice (KAP) theory, knowing the existence of a disease and acquiring accurate knowledge is the foundation of health behaviour. In this context, there is a need for China to provide more HIV health education for residents of underdeveloped rural areas after getting a grasp on the effects of existing HIV health education.

On the other hand, previous research on HIV knowledge might have led to an overestimation of the effects of HIV health education [13, 15]. This overestimation could be attributed to the phenomenon of previous researchers inviting participants to fill the official questionnaire on HIV knowledge without asking whether they knew what HIV was. Therefore, some participants may just become familiar with HIV while reading the questionnaire and, if they select the correct answers, they may be assessed as having knowledge of HIV. This might contribute to a higher rate of reported HIV awareness, especially for rural areas [15]. Therefore the lack of accurate data had to be compensated.

The aim of this study was to evaluate the coverage of HIV health education in rural China by ascertaining the awareness of HIV/AIDS and its transmission routes among local residents, and to further investigate how these residents receive health information. Geographically, China can be divided into the eastern, central, and western areas. Socioeconomic development of the western area has lagged far behind since the Chinese reform and opening in 1978 [16]. In 2000, China initiated the Western Development Program (WDP), which ultimately established "western China" as a political term for an area consisting of 12 provincial divisions. It is a vast area, having more than fifty minorities living together with the Han people. The natural environment, and cultural and socioeconomic conditions, are more complex in the western part of the country than in the eastern and central areas, and these factors make health education more complicated [17]. Administratively, western China could also be categorized into two sections under a historical urban-rural dual structure. The rural area of western China is the least developed area. We conducted this research in rural western China.

\section{Methods}

\section{Study area and setting}

The study was conducted in 11 provincial administrative divisions (hereinafter "provinces") in western China, in December 2011, as shown in Table 1. Western China covers $72 \%$ of the country's territory, for a total of 6.86 million square kilometres. Most of this area consists of highland which is more than $1000 \mathrm{~m}$ above sea level. This area has a border approximately 20 thousand kilometres long and is contiguous to 10 countries, where two of the world's main drug resources are located - the Golden Triangle and the Golden Crescent. It includes 6 provinces, 5 minority autonomous regions, and 1 municipality. Previously, Yunnan, 
Table 1 Construction of regional factors

\begin{tabular}{|c|c|c|c|c|c|c|c|}
\hline Province & $\begin{array}{l}\text { Category } \\
\text { a }\end{array}$ & $\begin{array}{l}\text { Area }(10, \\
\left.000 \mathrm{~km}^{2}\right) \\
\mathrm{e}\end{array}$ & $\begin{array}{l}\text { Population } \\
\text { (million) }^{f}\end{array}$ & $\begin{array}{l}\text { Proportion of } \\
\text { rural population } \\
(\%)^{f}\end{array}$ & $\begin{array}{l}\text { Per capital annual net income } \\
\text { of rural households (RMB) }{ }^{\mathrm{g}, \mathrm{b}}\end{array}$ & $\begin{array}{l}\text { Proportion of } \\
\text { minority population } \\
(\%)^{f, c}\end{array}$ & $\begin{array}{l}\text { Cumulative cases of HIV/ } \\
\text { AIDS (in thousands of cases) } \\
h, d\end{array}$ \\
\hline Gansu & Province & 42.58 & 25.99 & 64.1 & 3909.37(B) & $9.43 \%(\mathbf{c})$ & $1-5(\mathbf{1})$ \\
\hline Guangxi & A.R. & 23.76 & 47.96 & 60.0 & $5232.33(\mathbf{B})$ & $37.18 \%(\mathbf{b})$ & $50-100(3)$ \\
\hline Guizhou & Province & 17.61 & 35.30 & 66.2 & $4145.35(\mathbf{A})$ & $36.11 \%(\mathbf{b})$ & $10-50(2)$ \\
\hline $\begin{array}{l}\text { Inner } \\
\text { Mongolia }\end{array}$ & A.R. & 118.3 & 25.11 & 44.5 & $6641.56(\mathbf{C})$ & $20.46 \%(\mathbf{b})$ & $1-5(\mathbf{1})$ \\
\hline Ningxia & A.R. & 6.64 & 6.68 & 52.0 & 5409.95(B) & $35.42 \%(\mathbf{b})$ & less than 1(1) \\
\hline Qinghai & Province & 72.23 & 5.88 & 55.3 & $4608.46(\mathbf{A})$ & $46.98 \%(\mathbf{b})$ & $1-5(\mathbf{1})$ \\
\hline Shaanxi & Province & 20.58 & 37.93 & 54.3 & $5027.87(\mathbf{B})$ & $0.51 \%(\mathbf{c})$ & $5-10(\mathbf{2})$ \\
\hline Sichuan & Province & 48.6 & 82.04 & 59.8 & $6128.55(\mathbf{C})$ & $6.1 \%(\mathbf{c})$ & $50-100(3)$ \\
\hline Tibet & A.R. & 120.22 & 3.24 & 77.3 & $4904.28(\mathbf{A})$ & $91.83 \%(\mathbf{a})$ & less than 1(1) \\
\hline Xinjiang & A.R. & 166 & 23.60 & 57.2 & $5442.15(B)$ & $59.9 \%(\mathbf{b})$ & $10-50(2)$ \\
\hline Yunnan & Province & 39.4 & 47.42 & 65.3 & 4721.99(A) & $33.37 \%(\mathbf{b})$ & 100 and above (3) \\
\hline
\end{tabular}

${ }^{a}$ A.R.: Autonomous Region

${ }^{b}$ Regional rural residents' economic status (RMB): A. Low-income area (less than 5000); B. Middle-income area (5000-6000); C. High-income area (6000 and above)

c Regional ethnic composition: a. Han-dominated area (less than 10\%); b. Mixed area (30-60\%); c. Minority-dominated area (90\% and above)

${ }^{\mathrm{d}}$ Regional HIV prevalence (in thousands of cases): 1. Low-prevalence area (less than 5); 2. Middle-prevalence area (5-50); 3. High-prevalence area (50 and above)

e The State Council of the People's Republic of China. http://english.gov.cn/archive/

${ }^{f}$ The Sixth National Population Census, 2010

${ }^{9}$ China National Bureau of Statistics. China Statistical Yearbook 2012[M]. Beijing: China Statistic Press; 2012

${ }^{\mathrm{h}}$ Long Yuqin. Picture: Distribution map of provincial cumulative HIV/AIDS (number of deaths included) until Oct 2014. China HIV map: homosexual transmission accounts for more than 80\%. http://news.ifeng.com/a/20141202/42619936_0.shtml

Guangxi, and Sichuan were ranked among the top five provinces with newly diagnosed HIV cases via heterosexual transmission and intravenous drug injection [11, 12], and an outbreak of HIV also occurred in Xinjiang around 2000 [18]. One third of the Chinese population lives in this area (approximately 360 million people), and nearly 60\% live in rural areas [19], including more than 50 minorities [16] with their own cultures, customs, and norms. Some also have unique languages and religions [20-22]. Religious influence is greater in this area than in the eastern or central areas - Islam forms a northwest-southeast belt extending from Xinjiang to Ningxia, whereas Buddhism forms a southwest-northeast belt extending from Tibet to Inner Mongolia [23]. Economic development, as a factor of HIV prevalence in Asian countries, is disrupting traditional society [24]. For better economic status, a large rural population moves inside this area as well as between other parts of China [11, 14, 16]. Additionally, drug trafficking, which originates in the Golden Triangle and Golden Crescent, moves from the northwestern and southwestern borders toward the coast [10], also adds pressure on HIV prevention. Finally, health care services in rural western China are insufficient - the quantity and quality of medical institutions are low, the service radius is large, the drug supply is scarce, and technical resources are limited [17].

\section{Questionnaire design}

For this study, we used a questionnaire written in Chinese, containing three sections. The first section was on sociodemographic information, including gender, age, education, occupation, and personal monthly income. Participants were classified into age groups of 16-40 years, 40-60 years, and above 60 years. Education was categorized into four levels - illiterate, primary, secondary, and tertiary, with reference to the revised 2011 version of the International Standard Classification of Education [25]. Occupation was classified according to the source of income, and personal monthly income classification was based on communication with local officials. The second section included 2 questions on HIV/AIDS: (1) Have you ever heard about HIV/AIDS (or do you know of the existence of HIV/AIDS)? (2) Please select all the transmission routes of HIV among blood, sex, mother-to-child, shaking hands, and droplets (multi-choice). Because implementation of the HIV health education relied on the general health education system, the third section of the questionnaire included 4 questions on access to health knowledge. Two questions were about direct access: (3) Please select the most frequently used channels to health knowledge based on your own situation among medical staff, mass media (broadcast, TV, newspapers, magazines, etc.), family members, and socializing (friends, colleagues, classmates, etc.) (multi-choice). (4) Did you participate in any health education activities in the last 6 months? Another two questions were on indirect access: (5) Have you had any physical examinations during the last year? (6) Have you had any non-communicable disease (NCD) during the last 6 months and, if so, did you receive any professional medical instructions? The 4 questions 
above were generated from previous studies [26-28] and adapted to our study setting. A pilot study was conducted with a small sample of the population before the main study was conducted.

\section{Sampling strategy}

In every province, according to the gross regional product (GRP) ranking, three counties representing high, middle, and low economic status were randomly selected $(3 \times 11=33$ counties). County GRPs were obtained from the statistics bureau. In 2011, more than 95\% of rural residents participated in the New Rural Cooperative Medical System (NRCMS). Sick individuals could be reimbursed for $60-80 \%$ of their medical costs if they visited local public medical institutions. In the current Chinese health system, county-level medical institutions are the primary comprehensive hospitals, and most patients treated there are local residents. Since household surveys and telephone surveys were not practical due to geographic and language barriers, we performed a hospital-based questionnaire study at public county-level medical institutions. Normally, each county has 3 types of county-level public medical institutions, so that 99 were included $(3 \times 3 \times 11=99$ county medical institutions). Questionnaires were randomly distributed to patients at the selected medical institutions through a systematic sampling process according to their order of registration. Sample size at specific medical institutions was calculated according to its annual patient volume.

\section{Quality control}

Questionnaires were administered by trained students from local medical colleges. Surveyors followed standardized procedures, with strategies to overcome the barriers of dialect, culture, and religion. Ethical approval was obtained from the University of Macau. All participants were fully informed of the research, and written informed consent was obtained. Additionally, the investigator could help explain the questionnaire; in some cases, the patients' companions or medical staff could help overcome the barriers of dialect or ethnical languages.

\section{Statistical analysis}

Descriptive statistics were used to define demographic characteristics. Chi-square analysis was used to analyse rate of awareness of HIV/AIDS (hereinafter, "HIV awareness rate") among different subgroups. Through chi-square analysis, factors that significantly affected awareness of HIV/AIDS were put into a binary logistic regression equation by the conditional forward method, therefore allowing us to analyse the influence of access to health knowledge on HIV awareness. Chi-square was used to analyse the influence of access to health knowledge on awareness of HIV transmission routes. SPSS
(Statistical Package for Social Sciences, Chicago, IL, USA), version 19.0, was used for statistical analysis. All statistical tests were two-sided, with a significance level of 0.05 .

\section{Results}

\section{Sociodemographic features}

A total of 10,394 questionnaires were returned, and 9274 (89.2\%) were valid. Among the 9274 participants, the age distribution quartile was 28,40 , and 53 years (range, 16-100) and $42.8 \%$ were male. Other sociodemographic features are shown in Table 2.

\section{HIV awareness}

For the 9274 participants, HIV awareness rate (the rate of knowing of the existence of HIV) was $80.9 \%$ [95\% CI: 80.1-81.7\%]. Subgroup analysis was applied to regional factors, sociodemographic factors, and access to health knowledge. Three regional factors, regional rural residents' economic status, regional ethnic composition, and regional HIV prevalence were constructed, respectively, by province-level of per capita annual net income of rural households, proportion of minority population, and cumulative cases of HIV/AIDS. Details are shown in Table 1. In the analysis of regional factors, participants' HIV awareness rate increased with increase in cumulative cases of HIV/AIDS, from 77.1 to $84.3 \%\left(\chi^{2}=59.513\right.$, $p<0.001)$. Per capita annual net income of rural households also had a positive influence on HIV awareness, with a cut-off point at 6000RMB $\left(\chi^{2}=64.676, p<0.001\right)$. Simultaneously, awareness rate was lower in regions with more ethnic minorities, ranging from $86.2 \%$ in a Han-dominated area to $74.1 \%$ in Tibet $\left(\chi^{2}=94.898, p<\right.$ 0.001 ), where more than $90 \%$ residents are minorities. Inpatient and outpatient status had no statistically significant effect on HIV awareness rates, and no difference was seen between the two genders. However, HIV awareness rate declined with increasing age, from $88.7 \%$ in young people (16-40 years) to $75.1 \%$ in middle-aged individuals (40-60 years), and $65.1 \%$ in the elderly (above 60 years) $\left(\chi^{2}=482.118, p<0.001\right)$. In contrast, we noted an upward trend from 60.0 to $96.1 \%$ with participants' educational levels increasing from less than primary education (the illiterate) to tertiary education $\left(\chi^{2}=\right.$ $853.465, p<0.001$ ), as well as from 74.1 to $89.2 \%$ with participants' personal monthly income increasing from no income to RMB4000 and above $\left(\chi^{2}=186.448, p<\right.$ 0.001). Three levels of HIV awareness rate were noted among different occupations $\left(\chi^{2}=340.533, p<0.001\right)$ : farmers and unemployed individuals (approximately 75\%), migrant workers and others (approximately 87\%), and students and salary employees (greater than 90\%). Individually, the HIV awareness rates were 88.8, 87.9, and $86.9 \%$ of participants who received health 
Table 2 Demographic features and Chi-square test for HIV awareness among rural residents in western China $(N=9274)$

\begin{tabular}{|c|c|c|c|c|c|}
\hline$\underline{\text { Variables }}$ & $N$ & Proportion of population (\%) & Rate of awareness (\%) & $x^{2}$ & $p$ value \\
\hline \multicolumn{6}{|l|}{ Patient type } \\
\hline Inpatient & 4345 & 46.9 & 80.8 & \multirow[t]{2}{*}{0.079} & \multirow[t]{2}{*}{0.778} \\
\hline Outpatient & 4929 & 53.1 & 81.0 & & \\
\hline \multicolumn{6}{|l|}{ Social-demographic variables } \\
\hline \multicolumn{6}{|l|}{ Gender } \\
\hline Male & 3965 & 42.8 & 80.4 & \multirow[t]{2}{*}{1.137} & \multirow[t]{2}{*}{0.286} \\
\hline Female & 5309 & 57.2 & 81.3 & & \\
\hline \multicolumn{6}{|l|}{ Age } \\
\hline $16-40$ & 4962 & 53.5 & 88.7 & \multirow[t]{3}{*}{$482.118^{* * *}$} & \multirow[t]{3}{*}{$<0.001$} \\
\hline $41-60$ & 2925 & 31.5 & 75.1 & & \\
\hline above 60 & 1387 & 15.0 & 65.1 & & \\
\hline \multicolumn{6}{|l|}{ Education } \\
\hline Illiteracy & 1304 & 14.1 & 60.0 & \multirow[t]{4}{*}{$853.465^{* * *}$} & \multirow[t]{4}{*}{$<0.001$} \\
\hline Primary & 2233 & 24.1 & 70.5 & & \\
\hline Secondary & 4523 & 48.8 & 88.0 & & \\
\hline Tertiary & 1214 & 13.1 & 96.1 & & \\
\hline \multicolumn{6}{|l|}{ Occupation } \\
\hline Farmer & 4284 & 46.2 & 74.0 & \multirow[t]{6}{*}{$340.533^{* * *}$} & \multirow[t]{6}{*}{$<0.001$} \\
\hline Migrant worker & 1379 & 14.9 & 87.9 & & \\
\hline Salary employee & 1121 & 12.1 & 91.8 & & \\
\hline Student & 324 & 3.5 & 94.8 & & \\
\hline Others & 1338 & 14.4 & 86.3 & & \\
\hline Unemployed individuals & 828 & 8.9 & 75.6 & & \\
\hline \multicolumn{6}{|l|}{ Personal monthly income } \\
\hline No income & 2621 & 28.3 & 74.1 & \multirow[t]{4}{*}{$186.448^{* * *}$} & \multirow[t]{4}{*}{$<0.001$} \\
\hline Less than 2000 yuan & 4127 & 44.5 & 80.3 & & \\
\hline 2000-4000 yuan & 1981 & 21.4 & 88.9 & & \\
\hline 4000 yuan and above & 545 & 5.9 & 89.2 & & \\
\hline \multicolumn{6}{|l|}{ Region } \\
\hline \multicolumn{6}{|l|}{ Cumulative cases of HIV/AIDS } \\
\hline Less than 5000 & 3458 & 37.3 & 77.1 & \multirow[t]{3}{*}{$59.513^{* * *}$} & \multirow[t]{3}{*}{$<0.001$} \\
\hline $5000-50,000$ & 2064 & 22.3 & 81.0 & & \\
\hline 50,000 and above & 3752 & 40.5 & 84.3 & & \\
\hline \multicolumn{6}{|c|}{ Per capita annual net income of rural households } \\
\hline Less than 5000 yuan & 3654 & 39.4 & 80.1 & $64.676^{* * *}$ & $<0.001$ \\
\hline $5000-6000$ yuan & 3619 & 39.0 & 78.3 & & \\
\hline 6000 yuan and above & 2001 & 21.6 & 87.0 & & \\
\hline Proportion of minority popt & & & & & \\
\hline Less than $10 \%$ & 3191 & 34.4 & 86.2 & $94.898^{* * *}$ & $<0.001$ \\
\hline $30-80 \%$ & 5512 & 59.4 & 78.5 & & \\
\hline $90 \%$ and above & 571 & 6.2 & 74.1 & & \\
\hline Access to HIV knowledge & & & & & \\
\hline NCD (in the last 6 months) & & & & & \\
\hline Do not have an NCD & 6889 & 74.3 & 81.1 & $78.709^{* * *}$ & $<0.001$ \\
\hline
\end{tabular}


Table 2 Demographic features and Chi-square test for HIV awareness among rural residents in western China ( $N=9274)($ Continued)

\begin{tabular}{|c|c|c|c|c|c|}
\hline Variables & N & Proportion of population (\%) & Rate of awareness (\%) & $x^{2}$ & $p$ value \\
\hline Living with an NCD with medical instructions & 1930 & 20.8 & 83.8 & & \\
\hline Living with an NCD without medical instructions & 455 & 4.9 & 65.7 & & \\
\hline \multicolumn{6}{|l|}{ Had a physical examination (in the last year) } \\
\hline Yes & 3515 & 37.9 & 87.0 & $135.679^{* * *}$ & $<0.001$ \\
\hline No & 5759 & 62.1 & 77.2 & & \\
\hline \multicolumn{6}{|l|}{ Participated in health education activities (in last 6 months) } \\
\hline Yes & 2951 & 31.8 & 88.3 & $154.400^{* * *}$ & $<0.001$ \\
\hline No & 6323 & 68.2 & 77.4 & & \\
\hline \multicolumn{6}{|l|}{ Received health knowledge from medical staff } \\
\hline Yes & 4872 & 52.5 & 88.8 & $419.755^{* * *}$ & $<0.001$ \\
\hline No & 4402 & 47.5 & 72.1 & & \\
\hline \multicolumn{6}{|l|}{ Received health knowledge from the mass media } \\
\hline Yes & 6653 & 71.7 & 87.9 & $740.238^{* * *}$ & $<0.001$ \\
\hline No & 2621 & 28.3 & 63.2 & & \\
\hline \multicolumn{6}{|l|}{ Received health knowledge from family members } \\
\hline Yes & 795 & 8.6 & 76.2 & $12.189^{* * *}$ & $<0.001$ \\
\hline No & 8479 & 91.4 & 81.3 & & \\
\hline \multicolumn{6}{|l|}{ Received health knowledge by socializing } \\
\hline Yes & 1696 & 18.3 & 86.9 & $48.780^{* * *}$ & $<0.001$ \\
\hline No & 7578 & 81.7 & 79.5 & & \\
\hline Overall & 9274 & 100.0 & 80.9 & - & - \\
\hline
\end{tabular}

knowledge from medical staff, mass media, or socializing, respectively, which were all greater than for those who did not. Participants who took part in health education activities and physical examinations both had a $10 \%$ higher awareness rate than those who did not. Conversely, those who received health knowledge from family members had a 5\% lower HIV awareness rate than those who did not. We noted that only 795 participants belonged to this subgroup, accounting for $8.6 \%$ of the sample population. Participants who had an NCD in the previous 6 months and received medical instructions had the similar level of awareness (83.8\%) as those who did not have an NCD (81.1\%). In contrast, only $65.7 \%$ of participants who had an NCD but did not receive medical instructions knew of the existence of HIV. These results are shown in Table 2.

\section{Factors associated with HIV awareness}

Except for patient type and gender, all demographic factors, regional factors, and methods of access to health knowledge were entered into a binary logistic regression model as dependent variables. HIV awareness rate was adopted as the independent variable. For demographic variables, participants who were 16 to 40 years old, illiterate, farmers, and had no income were the reference groups, respectively, for the categories of age, education, occupation, and personal monthly income. For regional variables, one variable - regional rural residents' economic status - was excluded by forward conditional analysis. Low-prevalence area and low proportion of minority population were the reference groups, respectively, for regional HIV prevalence and regional ethnic composition. For access to health knowledge, the reference groups were those with individuals who did not receive health knowledge from medical staff, mass media, family members, and socializing; those who did not participate in health education activities; those who did not have a physical examination; and those who did not have an NCD. As shown in Table 3, compared with young people (16-40 years), middle-aged individuals (41-60 years) were less likely to know about $\mathrm{HIV}(\mathrm{OR}=0.533$, 95\% CI: $0.462-0.615, p<0.001)$ and older people $(60$ years and above) were even less likely (OR $=0.395,95 \%$ CI: 0.329-0.474, $p<0.001)$. Compared with farmers, students were more likely to know about HIV $(\mathrm{OR}=2.469$, 95\% CI: $1.455-4.188, p<0.01)$. Compared with the illiterate, those who had finished secondary education were more likely to know about HIV (OR $=2.275$, 95\% CI: 1.903-2.720, $p<0.001$ ), and having finished tertiary education increased this likelihood $(\mathrm{OR}=4.519,95 \% \mathrm{CI}$ : 
Table 3 Logistic regression results of HIV awareness among rural residents in western China $(N=9274)$

\begin{tabular}{|c|c|c|c|c|}
\hline \multirow[t]{2}{*}{ Variables } & \multirow[t]{2}{*}{ OR } & \multicolumn{2}{|l|}{$\underline{95 \% \mathrm{Cl}}$} & \multirow[t]{2}{*}{$p$ value } \\
\hline & & Lower & Upper & \\
\hline \multicolumn{5}{|l|}{ Social-demographic variables } \\
\hline \multicolumn{5}{|l|}{ Age } \\
\hline $16-40$ & 1 & & & \\
\hline $41-60$ & 0.533 & 0.462 & 0.615 & $<0.001$ \\
\hline Above 60 & 0.395 & 0.329 & 0.474 & $<0.001$ \\
\hline \multicolumn{5}{|l|}{ Education } \\
\hline Illiterate & 1 & & & \\
\hline Primary & 1.340 & 1.137 & 1.579 & $<0.001$ \\
\hline Secondary & 2.275 & 1.903 & 2.720 & $<0.001$ \\
\hline Tertiary & 4.519 & 3.130 & 6.525 & $<0.001$ \\
\hline \multicolumn{5}{|l|}{ Occupation } \\
\hline Farmer & 1 & & & \\
\hline Migrant worker & 1.137 & 0.928 & 1.394 & 0.215 \\
\hline Salary employee & 1.346 & 1.017 & 1.783 & 0.038 \\
\hline Student & 2.469 & 1.455 & 4.188 & 0.001 \\
\hline Others & 1.349 & 1.093 & 1.666 & 0.005 \\
\hline Unemployed individuals & 1.315 & 1.072 & 1.614 & 0.009 \\
\hline \multicolumn{5}{|l|}{ Personal monthly income } \\
\hline No income & 1 & & & \\
\hline Less than 2000 yuan & 1.449 & 1.254 & 1.764 & $<0.001$ \\
\hline 2000-4000 yuan & 1.636 & 1.323 & 2.021 & $<0.001$ \\
\hline 4000 yuan and above & 1.412 & 1.011 & 1.971 & 0.043 \\
\hline \multicolumn{5}{|l|}{ Region } \\
\hline \multicolumn{5}{|l|}{ Cumulative cases of HIV/AIDS } \\
\hline Less than 5000 & 1 & & & \\
\hline $5000-50,000$ & 0.722 & 0.608 & 0.856 & $<0.001$ \\
\hline 50,000 and above & 1.024 & 0.882 & 1.188 & 0.760 \\
\hline \multicolumn{5}{|l|}{ Proportion of minority population } \\
\hline Less than $10 \%$ & 1 & & & \\
\hline $30-80 \%$ & 0.864 & 0.751 & 0.995 & 0.042 \\
\hline $90 \%$ and above & 0.453 & 0.347 & 0.591 & $<0.001$ \\
\hline \multicolumn{5}{|l|}{ Access to health knowledge } \\
\hline \multicolumn{5}{|l|}{ NCD (in the last 6 months) and medical instructions } \\
\hline Do not have an NCD & 1 & & & \\
\hline Living with an NCD with medical instructions & 1.218 & 1.023 & 1.451 & 0.027 \\
\hline Living with an NCD without medical instructions & 0.689 & 0.542 & 0.875 & 0.002 \\
\hline \multicolumn{5}{|l|}{ Had a physical examination (in the last year) } \\
\hline Yes & 1.310 & 1.125 & 1.525 & $<0.001$ \\
\hline No & 1 & & & \\
\hline \multicolumn{5}{|l|}{ Participated in health education activities (in last 6 months) } \\
\hline Yes & 1.413 & 1.204 & 1.658 & $<0.001$ \\
\hline No & 1 & & & \\
\hline
\end{tabular}

Received HIV knowledge from medical staff 
Table 3 Logistic regression results of HIV awareness among rural residents in western China $(N=9274)$ (Continued)

\begin{tabular}{|c|c|c|c|c|}
\hline \multirow[t]{2}{*}{ Variables } & \multirow[t]{2}{*}{ OR } & \multicolumn{2}{|l|}{$95 \% \mathrm{Cl}$} & \multirow[t]{2}{*}{$p$ value } \\
\hline & & Lower & Upper & \\
\hline Yes & 2.557 & 2.244 & 2.914 & $<0.001$ \\
\hline No & 1 & & & \\
\hline \multicolumn{5}{|c|}{ Received HIV knowledge from the mass media } \\
\hline Yes & 3.812 & 2.800 & 3.618 & $<0.001$ \\
\hline No & 1 & & & \\
\hline \multicolumn{5}{|c|}{ Received HIV knowledge from family members } \\
\hline Yes & 0.816 & 0.669 & 0.996 & 0.046 \\
\hline No & 1 & & & \\
\hline \multicolumn{5}{|c|}{ Received HIV knowledge by socializing } \\
\hline Yes & 1.524 & 1.282 & 1.812 & $<0.001$ \\
\hline No & 1 & & & \\
\hline
\end{tabular}

3.130-6.525, $p<0.001)$. People who received health knowledge from medical staff $(\mathrm{OR}=2.557,95 \% \mathrm{CI}$ : $2.244-2.914, p<0.001)$ and the mass media $(\mathrm{OR}=3.812$, 95\% CI: $2.800-3.618, p<0.001)$ were more likely to know about HIV. Interestingly, people in high-prevalence areas and low-prevalence areas had the same likelihood of being aware about $\mathrm{HIV}(\mathrm{OR}=1.024,95 \%$ CI: 0.882-1.188, $p=0.760)$, whereas those in middle-prevalence areas were less likely to know about $\mathrm{HIV}(\mathrm{OR}=0.722,95 \% \mathrm{CI}$ : $0.608-0.856, p<0.001)$. Finally, the likelihood of knowing of HIV decreased with an increased proportion of minorities (minority proportion according to province 30$80 \%$ : $\mathrm{OR}=0.864$; minority proportion according to province $>90 \%$ : $\mathrm{OR}=0.453$ ).

\section{Relationship between access to health knowledge and awareness of HIV transmission routes}

Table 4 shows the awareness rates of HIV transmission routes among different subgroups. When comparing the awareness rates of the three transmission routes among subgroups in each category of access to health knowledge, the mother-to-child route had the lowest level. Among all subgroups, the awareness rates of mother-tochild route were more than $10 \%$ smaller than the other two routes. In the aspect of subgroup analysis, low levels of awareness were showed of all three transmission routes among those who did not receive health knowledge from medical staff (blood, mother-to-child, sex: $56.5,45.5,56.3 \%$, respectively) and mass media (blood, mother-to-child, sex: 48.5, 32.5, 46.1\%, respectively). However, the awareness level of all three transmission routes was lower among those who received health information from family members (blood, mother-to-child, sex: $64.5,53.5,63.6 \%$, respectively). Moreover, those who had an NCD without medical instructions also had low awareness levels; specifically, 51.0, 39.3, and 47.4\% for the blood route, mother-to-child route, and sex route, respectively.

\section{Discussion}

The results revealed that the overall HIV awareness rate was $80.9 \%$ and we noted the following differences according to age group: HIV awareness rates were 88.7, $75.1,65.1 \%$ among the young (16-40 years), middle-aged (41-60 years), and elderly (older than 60 years), respectively. Age was a suppressing factor for knowing of HIV/ AIDS in a regression model. This result corresponded to a sharp increase in HIV infection among the Chinese elderly in recent years [12]. This phenomenon was partly attributed to older men's engagement in commercial sex and older women's participation in extramarital sex, with poor knowledge of HIV [29]. Moreover, HIV health education for the elderly was neglected in the early years [29-31]. Thus, there was a need to improve HIV health education for this age group. The HIV awareness rate for farmers or unemployed individuals was approximately $75 \%$, which was about $10 \%$ less than for migrant workers and about $20 \%$ less than for students and salary employees. Personal monthly income had a positive effect on HIV awareness, but more than two thirds of participants had a personal monthly income of less than 2000RMB. When occupation and personal income were considered together, we found that those with the lowest income may need special attention. In the current economic structure of China, rural residents often leave home yearly for better wages as migrant workers. In comparison, those who remained unemployed or who stayed to work on farms fared worse in the labour market. Living in remote villages, they had insufficient health care resources and access to health information. Furthermore, considering the different categories, poor farmers and the unemployed, residents with no income, and those who had an NCD without professional medical 
Table 4 Relationship between access to health knowledge and awareness of HIV transmission routes $(N=9274)$

\begin{tabular}{|c|c|c|c|c|c|c|c|c|c|c|}
\hline Access to health knowledge & $\mathrm{N}$ & Blood (\%) & $x^{2}$ & $p$ value & Mother-to-Child (\%) & $x^{2}$ & $p$ value & Sex (\%) & $x^{2}$ & $p$ value \\
\hline \multicolumn{11}{|l|}{$\begin{array}{l}\text { NCD (in the last } 6 \text { months) and } \\
\text { medical instructions }\end{array}$} \\
\hline Do not have an NCD & 6889 & 69.0 & $65.931^{* * *}$ & $<0.001$ & 57.2 & $57.474^{* * *}$ & $<0.001$ & 69.3 & $96.467^{* * *}$ & $<0.001$ \\
\hline $\begin{array}{l}\text { Living with an NCD with } \\
\text { medical instructions }\end{array}$ & 1930 & 69.7 & & & 54.3 & & & 70.4 & & \\
\hline $\begin{array}{l}\text { Living with an NCD without } \\
\text { medical instructions }\end{array}$ & 455 & 51.0 & & & 39.3 & & & 47.7 & & \\
\hline \multicolumn{11}{|l|}{$\begin{array}{l}\text { Had a physical examination } \\
\text { (in the last year) }\end{array}$} \\
\hline Yes & 3515 & 74.0 & $87.052^{* * *}$ & $<0.001$ & 58.9 & $23.497^{* * *}$ & $<0.001$ & 75.4 & $126.968^{* * *}$ & $<0.001$ \\
\hline No & 5759 & 64.7 & & & 53.8 & & & 64.2 & & \\
\hline \multicolumn{11}{|l|}{$\begin{array}{l}\text { Participated in health education } \\
\text { activities (in last } 6 \text { months) }\end{array}$} \\
\hline Yes & 2951 & 76.1 & $125.255^{* * *}$ & $<0.001$ & 61.4 & $56.120^{* * *}$ & $<0.001$ & 76.1 & $117.298^{* * *}$ & $<0.001$ \\
\hline No & 6323 & 64.5 & & & 53.1 & & & 64.9 & & \\
\hline \multicolumn{11}{|l|}{$\begin{array}{l}\text { Received health knowledge } \\
\text { from medical staff }\end{array}$} \\
\hline Yes & 4872 & 78.9 & $535.575^{* * *}$ & $<0.001$ & 65.0 & $356.523^{* * *}$ & $<0.001$ & 79.4 & $570.262^{* * *}$ & $<0.001$ \\
\hline No & 4402 & 56.5 & & & 45.5 & & & 56.3 & & \\
\hline \multicolumn{11}{|l|}{$\begin{array}{l}\text { Received health knowledge } \\
\text { from mass media }\end{array}$} \\
\hline Yes & 6653 & 76.0 & $656.038^{* * *}$ & $<0.001$ & 64.9 & $802.594^{* * *}$ & $<0.001$ & 77.3 & $846.813^{* * *}$ & $<0.001$ \\
\hline No & 2621 & 48.5 & & & 32.5 & & & 46.1 & & \\
\hline \multicolumn{11}{|l|}{$\begin{array}{l}\text { Received health knowledge } \\
\text { from family members }\end{array}$} \\
\hline Yes & 795 & 64.5 & $5.475^{* * *}$ & 0.019 & 53.5 & 1.845 & 0.174 & 63.6 & $9.326^{* *}$ & 0.002 \\
\hline No & 8479 & 68.6 & & & 56.0 & & & 68.9 & & \\
\hline \multicolumn{11}{|l|}{$\begin{array}{l}\text { Received health knowledge } \\
\text { by socializing }\end{array}$} \\
\hline Yes & 1696 & 75.9 & $56.197^{* * *}$ & $<0.001$ & 64.0 & $57.762^{* * *}$ & $<0.001$ & 77.5 & $79.168^{* * *}$ & $<0.001$ \\
\hline No & 7578 & 66.5 & & & 53.9 & & & 66.4 & & \\
\hline Overall & 9274 & 67.8 & - & - & 55.4 & - & - & 68.1 & - & - \\
\hline
\end{tabular}

${ }^{* *} P<0.01,{ }^{* * *} P<0.001$

instructions, had a great overlap, and might be a same group of people. This small population may be the most impoverished, and more aggressive strategies should be taken to increase HIV awareness in this group, such as in-person education.

As to awareness of the routes of HIV transmission, sexual transmission and blood transmission were at similar awareness levels in each subgroup, out of all the categories classified according to access to health knowledge. In contrast, awareness of mother-to-child transmission was more than $10 \%$ lower than the other two routes in each subgroup. This finding was similar to those of other studies in the same region [32]. Other studies showed that China's program for preventing mother-to-child transmission (PMTCT) was effective on the basis of adequate publicity [1], and some cases of
PMTCT failure were attributed to lack of knowledge of HIV and the PMTCT program [33, 34]. The mother-tochild transmission route and the PMTCT program deserve more publicity.

Our results were consistent with previous research which showed that residents mainly rely on traditional sources of health knowledge in rural western China, such as medical personnel, radio and TV, magazines, and leaflets [17]. In this study, residents who received health knowledge from medical staff had the best results on questions about HIV transmission, and this result revealed that efforts to implement HIV health education relied too heavily on medical staff. The second source of information was mass media, which was also the most efficient. This result was consistent with other studies $[17,26]$, and called for mass media to take more 
responsibility in HIV health education and prevention. The third source of information was socializing. This finding was consistent with another result of this research which indicated that better performance was seen among those who had engaged in health education activities. However, due to the remote setting, it is not an efficient strategy to encourage frequent socializing and participation in activities in this area. Finally, only $8 \%$ said that they gained health knowledge from family members. The HIV awareness rate and the awareness rates for all three transmission routes among this small subgroup were more than $10 \%$ lower than the rates for the majority, which exposed a low level of health literacy in this area at the family or household level.

As mentioned above, this research indicated that the elderly and the most impoverished populations needed special attention in an individual aspect. Geographically, this research showed that regional economic development had little impact since the variable of regional rural residents' economic status was excluded from the regression model. Regions with complex ethnic compositions deserve more attention since the proportion of minority populations was a suppressing factor for HIV awareness. From a longitudinal viewpoint, it was still an issue of how to elevate the population's literacy level by educating the minorities within the community [35]. The results of this investigation also showed that education was the strongest factor promoting residents in rural areas to know about HIV and, hence, education was a key determinant of HIV awareness in the context of rural west China. Both general education and HIV health education were important [36]. Improving the general education level could diminish HIV discrimination, as well as enhance the ability of people of low socioeconomic status to understand health information [37, 38]. However, it was impossible to improve the level of general education at one strike in such a complicated area. Health education was more direct in cultivating behavioural changes concerning health and to improve health literacy. Chinese government regarded the systematic health education in schools as one of the key strategies to improve the health literacy of general population, anticipating the students to spread the right knowledge to their family members and communities [39]. On this basis, apart from multiple publicity access, the Chinese government strengthened HIV health education in schools [6]. Although few investigations focused on the effects of such a strategy on the family, it was rational to infer that educating the children would raise the awareness of parents through policy promotion and parent-child interaction. During the past several years, the Chinese government has mobilized university students to play an active role in HIV health education in a series of voluntary HIV prevention programmes [1].
Minority university students, especially those growing up in minority communities, had huge advantages in HIV education activities [40]. On this basis, the strategy of encouraging students to spread their knowledge of HIV at their homes or back in their hometowns should be strengthened.

\section{Limitations}

There were three major limitations to this study. First, all participants were patients at local public hospitals, which could introduce a bias from being in contacting with medical institutions. Second, the main source of health knowledge was general, especially mass media. More specific access to the source of information, for example through journals, broadcasts, online resources, or mobile devices, was not analysed. Third, demographic factors, regional factors, and access to health information were analysed individually, whereas empirically they were not mutually exclusive and their collaborative effects should be considered [41].

\section{Conclusion}

HIV health education covers $80 \%$ of the rural population in western China, and more active health education measures are needed for the elderly, the most impoverished population, and the minority community. Mass media should take greater responsibility in HIV health education for the general population. The mother-tochild transmission route called for special attention. In the long run, the strategy of delivering HIV knowledge through school students to their original communities and family members should be continuously encouraged. Strengthening education programs could have great importance in fostering HIV awareness.

\section{Abbreviations}

AIDS: Acquired immune deficiency syndrome; CSW: Commercial sex worker; GRP: Gross regional product; HIV: Human immunodeficiency virus;

IDU: Intravenous drug user; KAP: Knowledge-attitude-practice; NCD: Noncommunicable disease; NRCMS: New rural cooperative medical system; PMTCT: Prevention of mother-to-child transmission; SPSS: Statistical package for social sciences; STD: Sexually transmitted disease; WDP: Western development program

\section{Acknowledgements}

The authors would show the highest appreciation to the supports from all levels of health authorities, Centers for Disease Control, and other local health institutes in the organization for field study in the 11 provinces of western China, as well as sincerely thankfulness for 11 collaborative research teams in local universities. Gratefulness would also be given to all the participants for their cooperation.

\section{Author' contributions}

YB and LGL designed the study and organized the field study. TQZ analyzed the data, build the statistical model and drafted the manuscript. YM were analysis assistant and revised the initial drafts of the manuscript. All authors read and approved the final manuscript.

\section{Funding}

The study was supported by two research funds to YB from the University of Macau, which was MYRG106(Y1-L3)-ICMS13-BY and MYRG2015-00190-ICMS- 
QRCM. The funding body played no role in the design of the study and collection, analysis, and interpretation of data and in writing the manuscript.

\section{Availability of data and materials}

The datasets used and/or analyzed during the current study are available from the corresponding author on reasonable request.

\section{Ethics approval and consent to participate}

Ethical approval was obtained from the University of Macau. Participants were fully informed of the objective of this study as well as their information was for academic use only. Additionally, all juvenile participants were guided or aided by their custodians, and similar assistance also provided for some elderly participants to guarantee they fully understood the questionnaire's content and ethical issues. Written informed consent was obtained from all of the participants or their custodians.

\section{Consent for publication}

Not applicable.

\section{Competing interests}

The authors declare that they have no competing interests.

\section{Author details}

${ }^{1}$ Institute of Chinese Medical Sciences \& State Key Laboratory of Quality Research in Chinese Medicine, University of Macau, Avenida da Universidade, Taipa, Macau, China. ${ }^{2}$ College of Management, Ningxia Medical University, 1160 Shengli Street, Yinchuan, Ningxia Province, China.

Received: 23 January 2019 Accepted: 22 November 2019

Published online: 04 December 2019

\section{References}

1. National Health and Family Planning Commision of the People's Republic of China: 2015 China AIDS response progress report. 2015

2. Nutbeam D, Padmadas SS, Maslovskaya O, Wu ZW. A health promotion logic model to review progress in HIV prevention in China. Health Promot Int. 2013;30(2):270-80.

3. Dai ZC, Qi XQ, Shen J, Chen BZ, Zheng LQ. Historical summary of AIDS prevention policy and strategy development in China (1984-2009). Beijing: Peking Union Medical College Press; 2014.

4. Zeng Y. Health education and intervention are major strategies for AIDS control (in Chinese). Chin J Health Educ. 2003:19(11):846-8.

5. Department of Disease Control \& Ministry of Health, China: The notice of printing and delivering the principles for HIV/STD Health Education. 1998.

6. China State Council AIDS Working Committee: National HIV prevention and publicity working instruction action plan (2004-2008). 2004

7. Yadycar P, Kadear G, Liu JB. Investigation on developing health education of AIDS prevention in 25 mosques in Xinjiang (in Chinese). Bull Dis Control Preven (China). 2012;27(2):6-8.

8. Wu F, Zhang KL, Shan GL. An HIV/AIDS intervention programme with Buddhist aid in Yunnan Province. Chin Med J. 2010;123(8):1011-6.

9. Liu W, Liu Y, Twum P, Li SX. National equity of health resource allocation in China: data from 2009 to 2013. Int J Equity Health. 2016:15(1):68.

10. Qian ZH, Vermund SH, Wang N. Risk of HIV/AIDS in China: subpopulations of special importance. Sex Transm Infect. 2005;81(6):442-7.

11. Zhong $L Q$, Zeng G. Epidemic status of HIV/AIDS in rural area of China (in Chinese). Occup Health. 2014:30(23):3475-8.

12. Wang LY, Qin QQ, Ding ZW, Cai C, Guo W, Li DM, Li PL, Ge L, Chen FF, Cui $Y$. Current situation of AIDS epidemic in China (in Chinese). Chin J AIDS STD. 2017;23(4):330-3.

13. Lv K, Hu H, Hu YF, Xiong R, Ma YP, Liu J, Han MJ. Survey of AIDS knowledge level among rural and urban residents in 12 provinces in China (in Chinese). Chin J Health Educ. 2010;26(3):179-82

14. Hong Y, Stanton B, Li XM, Yang HM, Lin DH, Fang XY, Wang J, Mao R. Rural-tourban migrants and the HIV epidemic in China. AIDS Behav. 2006;10(4):421-30.

15. Wang Z, Zhang JY, Wan SP, Liu MY. A review of researches on AIDS related health education in rural areas (in Chinese). Chin J AIDS STD. 2013;19(2):158-60.

16. Lai HY. China's western development program: its rationale, implementation, and prospects. Modern China. 2002;28(4):432-66.
17. Yuan F, Qian DF, Huang CL, Tian MM, Xiang YX, He ZF, Feng ZC. Analysis of awareness of health knowledge among rural residents in Western China. BMC Public Health. 2015;15(1):55.

18. Zeng Q, Wang J, Dong Y, Du X, Cao Y, Wang J, Shen Q, Liu B, Tang X, Li Y. Analysis of monitoring data of AIDS in Xinjiang from 2004 to 2015 (in Chinese). Bull Dis Control Prevent (China). 2017;32(1):34-8.

19. Population Census Office under the State Council \& Department of Population and Employment Statistics, National Bureau of Statistics. Tabulation on the 2010 population census of the People's Republic of China. Beijing: China Statistics Press; 2010.

20. Deng R, Li JH, Sringernyuang L, Zhang KN. Drug abuse, HIV/AIDS and stigmatisation in a Dai community in Yunnan, China. Soc Sci Med. 2007; 64(8):1560-71.

21. Yang Y, Luan RS, Liu P, Wu CL, Zhou Y, Chen W. Casual sex and concurrent sexual partnerships among young people from an Yi community with a high prevalence of HIV in China. Asian J Androl. 2012;14(5):758-65.

22. Hayes A, Qarluq A. Securitising HIV/AIDS in the Xinjiang Uyghur Autonomous Region. Aust J Int Aff. 2011;65(2):203-19.

23. Alana Y.. This fascinating map shows the new religious breakdown in China. [https://www.businessinsider.com/new-religious-breakdown-in-china-14] Accessed on 4 Oct 2019

24. Sutherland D, Hsu J. HIV/AIDS in China - the economic and social determinants. London and New York: Routledge; 2011

25. UNESCO: International Standard Classification of Education: ISCED 2011.2012

26. Wong LP, Chin CKL, Low WY, Jaafar N. HIV/AIDS-related knowledge among Malaysian young adults: findings from a nationwide survey. J Int AIDS Soc. 2008;10(6):148.

27. Tanaka Y, Kunii O, Hatano T, Wakai S. Knowledge, attitude, and practice (KAP) of HIV prevention and HIV infection risks among Congolese refugees in Tanzania. Health Place. 2008;14(3):434-52.

28. Lin KC, Zhou MF. Rural areas of different levels of development of AIDS awareness (in Chinese). Chin Prim Health Care. 2010;24(2):57-60.

29. Wang LY, Qin QQ, Ge L, Ding ZW, Cai C, Guo W, Cui Y. Characteristics of HIV infections among over 50-year-olds population in China (in Chinese). Chin J Epidemiol. 2016:37(2):222-6.

30. Lu L, Jia MH, Ma YL, Yang L, Chen ZW, Ho DD, Jiang Y, Zhang LQ. The changing face of HIV in China. Nature. 2008:455(7213):609-11.

31. Xing JN, Li YG, Tang WM, Guo W, Ding ZW, Ding GW, Wang LY, Qin QQ, XU Y, Qian SS, et al. HIV/AIDS epidemic among older adults in China during 2005-2012: result from trend and spatial analysis. Clin Infect Dis. 2014;59(2):e53-60.

32. Wang $C$, Su XG, Song $W L$, Zhang $X H$, Wang $L$, Jiang $Y$, Zhang $L$, Cui $Y$. Knowledge about HIV/ADIS among urban and rural residents in 5 provinces of West China - a telephone survey (in Chinese). Chin J Public Health. 2013; 29(12):1735-8.

33. Zhang Y, Zhang G, Wu G, Liu W, Zhang Z, He C, He D, Wu F, He H. Analysis of 72 cases of HIV infection in children due to mother to child transmission prevention failures in Sichuan province (in Chinese). Journal of Preventive Medicine Information. 2019;35(3):219-22.

34. Li B, Zhao QG, Zhang XZ, Wu L, Chen TT, Liang ZJ, Xu LC, Yu SY. Effectiveness of a prevention of mother-to-child HV transmission program in Guangdong province from 2007 to 2010. BMC Public Health. 2013;13(1):591.

35. Han WC. The disscussion of regional traditional Chinese culture and the prevention \& control of AIDS in western ethnic zone (in Chinese). Med Philos. 2006:27(7):19-20.

36. Vandemoortele J, Delamonica E. The "education vaccine" against HIV. Cur Issues Comp Educ. 2000;3(1):6-13.

37. Tichenor PJ, Donohue GA, Olien CN. Mass media flow and differential growth in knowledge. Public Opin Quart. 1970;34(2):159-70.

38. Lee CJ. The role of internet engagement in the health-knowledge gap. J Broadcast Electron. 2009:53(3):365-82

39. Zhu B. Zhong guo gong min jian kang su yang yu xue xiao jian kang jiao yu zi yuan de zheng he li yong (in Chinese). Chin J School Health. 2009;30(2):161-2.

40. Hu Y. Min Zu Di Qu Gao Xiao Da Xue Sheng Jin Du Fang Ai Xuan Chuan Jiao Yu De Tan Suo (in Chinese). Educ Vocation. 2016:3:59-61.

41. Pellowski JA, Kalichman SC, Matthews KA, Adler N. A pandemic of the poor: social disadvantage and the U.S. HIV epidemic. Am Psychol. 2013;68(4):197-209.

\section{Publisher's Note}

Springer Nature remains neutral with regard to jurisdictional claims in published maps and institutional affiliations. 